\title{
Karakterisasi Simplisia dan Ekstrak Daun Pacar Kuku (Lawsonia inermis Linn) serta Penentuan Kadar Fenolat Total dan Uji Aktivitas Antioksidan
}

(Characterization of crude drugs and henna leaves extract (Lawsonia inermis Linn) and determination of total phenolic content and antioxidant activity test)

\author{
Elidahanum Husni*, Netty Suharti, \& Arlyn Pasella Tri Atma
}

Fakultas Farmasi Universitas Andalas

ABSTRACT: Lawsonia inermis Linn (henna leaves) is a medicinal plant from Lythraceae family. This plant has proven to be able to treat a variety of diseases. This study was aimed to characterize the crude drugs (simplisia) and ethanol extracts of henna leaves, determine the total phenolic content with Folin-Ciocalteau method and antioxidant activity with Ferric Reducing Antioxidant Power (FRAP). The extraction was performed using $70 \%$ ethanol. The crude drug was a powder, greenish brown color, bitter tasted and with distinctive odor. The loss of drying simplisia was $4.92 \% \pm 0.16$, total ash was $4.61 \% \pm 0.02$, acid insoluble ash was 4.43 $\% \pm 0.14$, water soluble concentration was $3.30 \% \pm 0.06$, and ethanol soluble concentration was $25.46 \% \pm 0.18$. Characterization of ethanol extracts was viscous, brown in color, typical odor and bitter tasted. The water content of ethanol extracts was $9.98 \% \pm$ 2.00 , total ash content was $2.63 \% \pm 0.91$, and non acid soluble ash content was $0.36 \% \pm 0.11$. The results of the determination of the total phenolics of ethanol extracts was $16.02 \mathrm{~g} / 100 \mathrm{~g}$. And antioxidant activity of ethanol extract was $2.85 \mathrm{mmol} \mathrm{Fe}$ (II)/100 g..

Keywords: lawsonia inermis; chracterization; total phenolics; antioxidant activity.

ABSTRAK: Lawsonia inermis Linn (pacar kuku) merupakan tumbuhan yang termasuk ke dalam famili Lythraceae. Secara farmakologi telah terbukti dapat mengobati berbagai penyakit. Penelitian ini bertujuan untuk mengetahui karakterisasi simplisia dan ekstrak etanol daun pacar kuku, menentukan kadar fenolat total dengan metoda Folin-Ciocalteau dan uji aktivitas antioksidan dengan metode Ferric Reducing Antioxidant Power. Daun pacar kuku diambil di daerah Padang, Sumatera Barat dan dimaserasi menggunakan pelarut etanol 70\% hingga didapatkan ekstrak etanol daun pacar kuku. Dari karakterisasi simplisia daun pacar kuku diketahui bahwa bentuknya serbuk, warna coklat kehijauan, rasa pahit dan bau yang khas. Parameter susut pengeringan simplisia diperoleh sebesar $4,92 \% \pm 0,16$, kadar abu total 4,61\% $\pm 0,02$, kadar abu tidak larut asam 4,43\% $\pm 0,14$, kadar sari larut air 3,30\% $\pm 0,06$, dan kadar sari larut etanol $25,46 \% \pm 0,18$. Karakterisasi ekstrak etanol daun pacar kuku secara organolpetis diketahui bahwa bentuknya cairan kental, warna coklat, rasa kelat dan bau yang khas. Parameter kadar air ekstrak etanol daun pacar kuku didapatkan sebesar 9,98\% $\pm 2,00$, kadar abu total 2,63\% $\pm 0,91$, dan kadar abu tidak larut asam 0,36\% $\pm 0,11$. Hasil penentuan kadar fenolat total ekstrak etanol daun pacar kuku adalah 16,02 g/100g. Aktivitas antioksidan ekstrak daun pacar kuku yaitu 2,85 $\mathrm{mmol} \mathrm{Fe}(\mathrm{II}) / 100 \mathrm{~g}$..

Kata kunci: lawsonia inermis; karakterisasi; fenolat total; aktivitas antioksidan.

\section{Pendahuluan}

Indonesia memiliki banyak tanaman yang mempunyai khasiat bagi kesehatan, salah satunya adalah tanaman pacar kuku (Lawsonia inermis Linn). Tanamannya berhabitus semak tinggi atau pohon kecil, tumbuh tegak, menahun dengan percabangan yang banyak, tinggi mencapai $6 \mathrm{~m}$, kulit batang abu-abu sampai cokelat, batang tidak berduri ketika masih muda, setelah tua berduri pada semua bagian cabang-cabangnya. Helaian daun tunggal, letak berhadapan, tepi daun rata dan tangkai daun pendek, bentuk helaian daun elip sampai lanset melebar. Bunga majemuk tandan,

berkumpul membentuk karangan bunga yang besar, bentuk piramid. Buah tanaman pacar kuku kapsul berbentuk bulat [1]. Tanaman pacar kuku mempunyai banyak khasiat seperti antimikroba, antioksidan, anti-iritan, anti karsinogenik, anti inflamasi, analgetik, dan antipiretik melalui pengujian in vitro dan in vivo [2,3]. Selain itu tanaman pacar kuku juga berfungsi sebagai antirheumatic, anti neuralgic agent [4] dan juga sebagai anti diabetic agent [5]. Tanaman ini memiliki kandungan utama senyawa aktif,

\section{Article history}

Received: 10 Jan 2018 Accepted: 12 April 2018 Published: 30 April 2018

Access this article

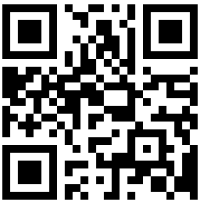


seperti alkaloid, glikosida, flavonoid, fenol, saponin, tanin, dan minyak atsiri. Fenol dan flavonoid merupakan senyawa aktif yang paling banyak ditemukan [2].

Beberapa penelitian tentang tanaman pacar kuku telah dilakukan salah satunya oleh Wiem et. al. [6] tentang fenolat total yang terdapat pada daun pacar kuku. Dilaporkan juga bahwa komponen fenol yang terdapat pada daun pacar kuku memiliki daya antioksidan [7]. Kualitas ekstrak yang dihasilkan sangat tergantung dari bahan tanaman, pemilihan pelarut dan metode ekstraksi [8].

Antioksidan adalah senyawa kimia pemberi elektron yang dapat meredam radikal bebas dengan cara memutuskan atau menghentikan reaksi berantai yang disebabkan oleh radikal bebas yang terdapat dalam tubuh [9]. Kandungan antioksidan yang terdapat pada tanaman bertindak sebagai radical scavenger dan membantu mengkonversikan radikal bebas yang kurang reaktif. Antioksidan alami yang terdapat pada seluruh bagian tanaman berupa karotenoid, vitamin, flavonoid, dan fenol. Antioksidan yang terdapat pada tanaman, menarik minat atas potensi gizi dan efek terapi yang dimilikinya [10]. Antioksidan dalam menghambat jalannya reaksi oksidasi dapat melalui beberapa cara, yaitu mekanisme donor proton, radical scavenger, oxygen quencher, dan inhibisi dengan enzim [11].

Tanaman yang sama belum tentu mempunyai aktivitas yang sama karena faktor geografis tempat tumbuh tanaman, iklim, cara pembudidayaan, cara dan waktu panen, dan cara perlakuan pascapanen (pengeringan dan penyimpanan) dapat mempengaruhi kandungan kimia tanaman [12,13]. Tanaman pacar kuku juga banyak tumbuh di kota Padang, Sumatera Barat, akan tetapi belum ada laporan tentang kandungan fenolat total dan aktivitas antioksidan dari tanaman ini. Berdasarkan hal tersebut akan dilakukan karakterisasi simplisia dan ekstrak untuk mengetahui mutu simplisia dan ekstrak dan dapat juga digunakan untuk melengkapi Farmakope Herbal Indonesia, serta penentuan fenolat total dan uji aktivitas antioksidan dari ekstrak etanol tanaman pacar kuku dengan metode FRAP (Ferric Reducing Antioxidant Power).

\section{Metode Penelitian}

Bahan

Daun segar Lawsonia inermis L, pelarut etanol 70\%, asam klorida $2 \mathrm{~N}$, kloroform, toluen, asam galat, reagen Folin-Ciocalteu, natrium karbonat, ortho-fenantrolin, aquadest, besi (II) sulfat heptahidrat, natrium asetat trihidrat, asam asetat pekat, besi (III) klorida heksahirat, etil asetat, aseton, asam asetat, etanol 96\%, dan kuersetin.

Penyiapan Ekstrak Daun Pacar Kuku

Sampel tanaman diambil dari daerah Lolong, Padang,
Sumatera Barat. Bagian tanaman yang diambil adalah daun segar sebanyak $1,5 \mathrm{~kg}$. Identifikasi tanaman dilakukan untuk memastikan spesies tanaman yang digunakan untuk penelitian. Identifikasi dilakukan di Herbarium Universitas Andalas Jurusan Biologi FMIPA Universitas Andalas.

Sebanyak $500 \mathrm{~g}$ serbuk daun pacar kuku dimasukan kedalam botol maserasi. Sampel diekstraksi dengan metoda maserasi dengan menggunakan pelarut etanol 70\%. Etanol ditambahkan sampai semua sampel terendam. Selama 6 jam pertama sampel sekali-kali diaduk, kemudian didiamkan selama 18 jam [14]. Pisahkan maserat dengan kertas saring. Proses penyarian diulangi tiga kali dengan jenis pelarut yang sama. Maserat yang diperoleh dipekatkan pada tekanan rendah menggunakan rotary evaporator (Buchi®) sehingga diperoleh ekstrak kental [15].

\section{Profil Kromatografi Lapis Tipis (KLT)}

Larutan sampel 1\% dilarutkan dalam pelarut etanol lalu digunakan kuersetin sebagai pembanding KLT. Fase gerak yang digunakan yaitu toluen:etil asetat:aseton (2:2:1) + 3 tetes asam asetat. Bercak dilihat pada lampu UV 254 $\mathrm{nm}, 365 \mathrm{~nm}$, dan dengan penampak bercak sitroborat.

\section{Karakterisasi Simplisia dan Ekstrak}

Karakterisasi dilakukan terhadap simplisia dan ekstrak. Pada simplisia dilakukan uji organoleptik, pemeriksaan mikroskopik, susut pengeringan, penetapan kadar sari larut air, penetapan kadar sari larut etanol, penetapan kadar abu total, dan penetapan kadar abu tidak larut asam. Ekstrak etanol daun pacar kuku dilakukan uji organoleptik, penetapan kadar abu total, penetapan kadar abu tidak larut asam, dan kadar air [16].

\section{Pemeriksaan Fenolat Total}

Larutan uji dipipet 0,1 mL, ditambahkan 0,9 mL aquadest $0,5 \mathrm{~mL}$ reagen Folin-Ciocalteu, lalu dikocok. Larutan ini didiamkan selama 5 menit dan ditambahkan 2,5 mL larutan $\mathrm{Na}_{2} \mathrm{CO}_{3} 20 \%$ ke dalam campuran dan dikocok homogen. Larutan didiamkan selama 26 menit pada suhu kamar. Nilai serapan diukur dengan spektrofotometer UV-Vis pada panjang gelombang serapan maksimum 765 nm. Pengulangan dilakukan sebanyak 3 kali sehingga kadar fenolat yang diperoleh hasilnya dinyatakan sebagai $g$ ekuivalen asam galat/100 g ekstrak sampel [17].

Identifikasi Aktivitas Antioksidan dengan Metode FRAP Sebanyak 0,1 mL larutan sampel dan $0,3 \mathrm{~mL}$ air suling ditambahkan ke dalam tabung yang telah berisi $3 \mathrm{~mL}$ reagen FRAP. Campuran di-vortex dan diinkubasi pada 
suhu 370C selama 30 menit di tempat gelap pada suhu ruang. Absorban sampel diukur pada panjang gelombang serapan maksimum $510 \mathrm{~nm}$. Larutan reagen FRAP dengan air suling tanpa sampel digunakan sebagai larutan blanko. Pengulangan dilakukan tiga kalisehingga aktivitas antioksidan sampel yang diperoleh dinyatakan dalam besi (II) ekuivalen $(\mathrm{Fe}+2 \mathrm{mM})$ menggunakan kurva standar besi sulfat heptahidrat.

\section{Hasil dan Diskusi}

Bahan daun pacar kuku segar diambil di Lolong, Padang, Sumatera Barat. Berdasarkan hasil identifikasi dapat diketahui bahwa tanaman yang diidentifikasi dan digunakan dalam penelitian ini adalah benar spesies Lawsonia inermis L. Selanjutnya dilakukan sortasi basah yang bertujuan untuk memisahkan kotoran (tanah, rumputrumput, serangga) dari sampel. Setelah itu dikeringkan di rumah kaca. Setelah kering dilakukan sortasi kering yang bertujuan untuk memisahkan kembali bagian tanaman atau kotoran yang tidak diinginkan yang masih tertinggal pada simplisia kering [18]. Setelah sortasi kering, didapatkan simplisia berupa daun kering dengan berat 600 gram. Selanjutnya simplisia kering dihaluskan dengan blender. Tujuan penghalusan yaitu untuk memperluas permukaan partikel simplisia sehingga semakin besar kontak permukaan partikel simplisia dengan pelarut dan mempermudah penetrasi pelarut ke dalam simplisia sehingga dapat menarik senyawa-senyawa dari simplisia lebih banyak.

Serbuk simplisia dimaserasi dengan pelarut etanol $70 \%$ hingga didapatkan ekstrak kental. Hasil ekstraksi simplisia diperoleh rendemen 36,05\% dari 500 gram simplisia. Dari penotolan ekstrak etanol daun pacar kuku pada lempeng kromatografi dan kuersetin sebagai pembanding menggunakan fase gerak toluen:etil asetat:aseton $(2: 2: 1)+3$ tetes asam asetat dan dilihat pada lampu UV $254 \mathrm{~nm}, 365 \mathrm{~nm}$, dan dengan penampak bercak sitroborat maka didapatkan Rf ekstrak yang sama dengan Rf pembanding, yaitu 0,65.

Secara organoleptik diketahui bentuk simplisia serbuk warna coklat kehijauan dengan rasa pahit dan bau yang khas. Secara mikroskopis terlihat fragmen epidermis bawah dengan stomata anomositik, sel minyak, berkas pembuluh, dan rambut penutup tipe jarum. Untuk susut pengeringan didapatkan sebesar 4,92\%, kadar sari larut air sebesar 3,29\% dan kadar sari larut etanol sebesar 25,46\%. Sedangkan untuk kadar abu total sebesar 4,61\% dan kadar abu tidak larut asam simplisia adalah sebesar 4,43\%.

Karakterisasi ekstrak etanol daun pacar kuku untuk

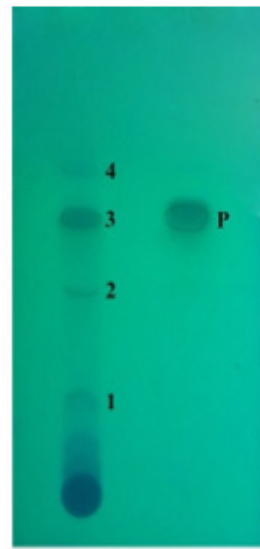

S

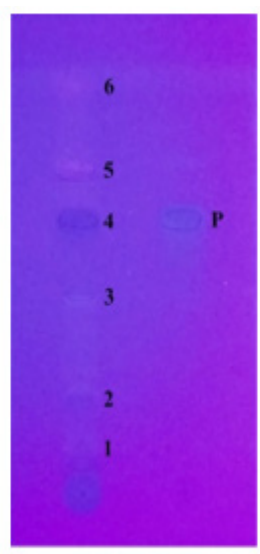

(b)

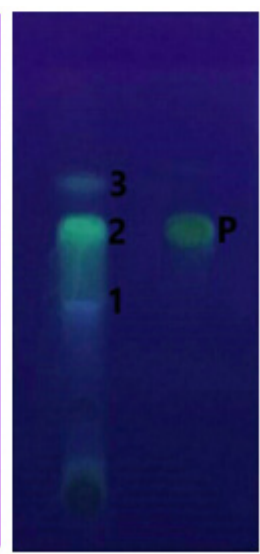

$\mathbf{S}$ (c)
Gambar 1. Ekstrak daun pacar kuku (a). Ekstrak daun pacar kuku pada deteksi UV 254 nm(b). Ekstrak daun pacar kuku pada deteksi UV 365 nm(c). ekstrak daunpacar kuku dengan penampak bercak sitroborat

penetapan kadar air ekstrak menunjukkan hasil 9,98\%, kadar abu total sebesar 2,63\%, dan kadar abu tidak larut asam ekstrak sebesar 0,36\%. Ekstrak etanol sebanyak $5 \mathrm{mg} / 10 \mathrm{ml}$ diuji dengan metode Folin-Ciocalteau pada panjang gelombang $765 \mathrm{~nm}$ mempunyai kadar fenolat total sebesar 16,02 g/100g. Metode Folin-Ciocalteau digunakan karena metode ini merupakan metode yang spesifik dan sensitif untuk senyawa fenol dan reagen yang digunakan dalam jumlah sedikit. Reagen Folin-Ciocalteau ini berwarna kuning kehijauan dan akan berubah menjadi warna biru tua jika direaksikan dengan larutan sampel yang telah ditambahkan dengan natrium karbonat [19]. Prinsip pengukuran kandungan fenolat dengan reagen Folin-Ciocalteau adalah terbentuknya senyawa kompleks berwarna biru yang dapat diukur pada panjang gelombang $765 \mathrm{~nm}$.

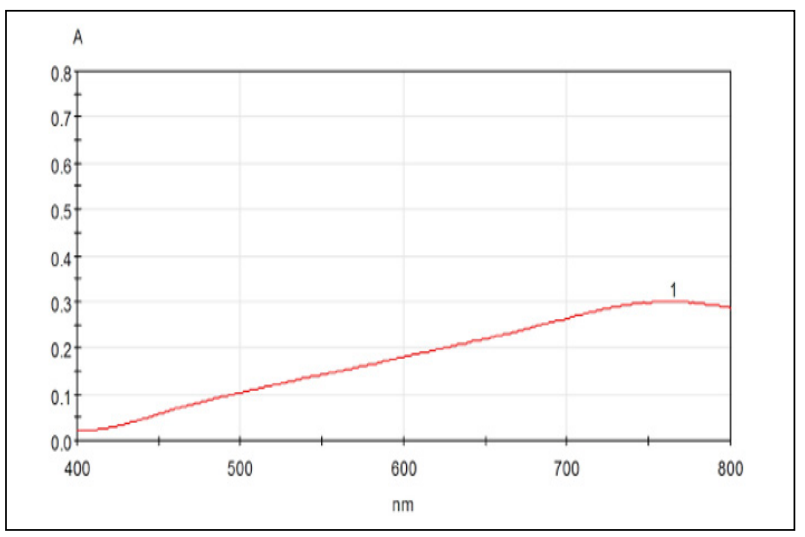

Gambar 2. Panjang gelombang serapan maksimum larutan standar asam galat dengan reagen Folin-Ciocalteau, (1) $765 \mathrm{~nm}$ wavelength, 0,300 abs. 
Table 1. Hasil perhitungan kadar fenolat total ekstrak daun pacar kuku dengan spektrofotometer UV-Vis $\lambda$ maks $765 \mathrm{~nm}$.

\begin{tabular}{|c|c|c|c|c|}
\hline Pengulangan & $\begin{array}{l}\text { Absorban } \\
\text { (y) }\end{array}$ & $\begin{array}{c}\text { Konsentrasi } \\
\text { (x) }\end{array}$ & $\begin{array}{l}\text { Konsentrasi rata-rata } \\
\text { (xi) }\end{array}$ & $\begin{array}{c}\text { Kadar Fenolat Total } \\
\qquad(\mathrm{g} / 100 \mathrm{~g})\end{array}$ \\
\hline \multirow{3}{*}{1} & 0,225 & 77,92 & & \\
\hline & 0,226 & 78,32 & 78,05 & 15,61 \\
\hline & 0,225 & 77,92 & & \\
\hline \multirow{3}{*}{2} & 0,239 & 83,52 & & \\
\hline & 0,237 & 82,72 & 82,85 & 16,57 \\
\hline & 0,236 & 82,32 & & \\
\hline \multirow{4}{*}{3} & 0,229 & 79,52 & & \\
\hline & 0,228 & 79,12 & 79,39 & 15,88 \\
\hline & 0,229 & 79,52 & & \\
\hline & Rata-rata & & 80,10 & $16,02 \pm 0,17$ \\
\hline
\end{tabular}

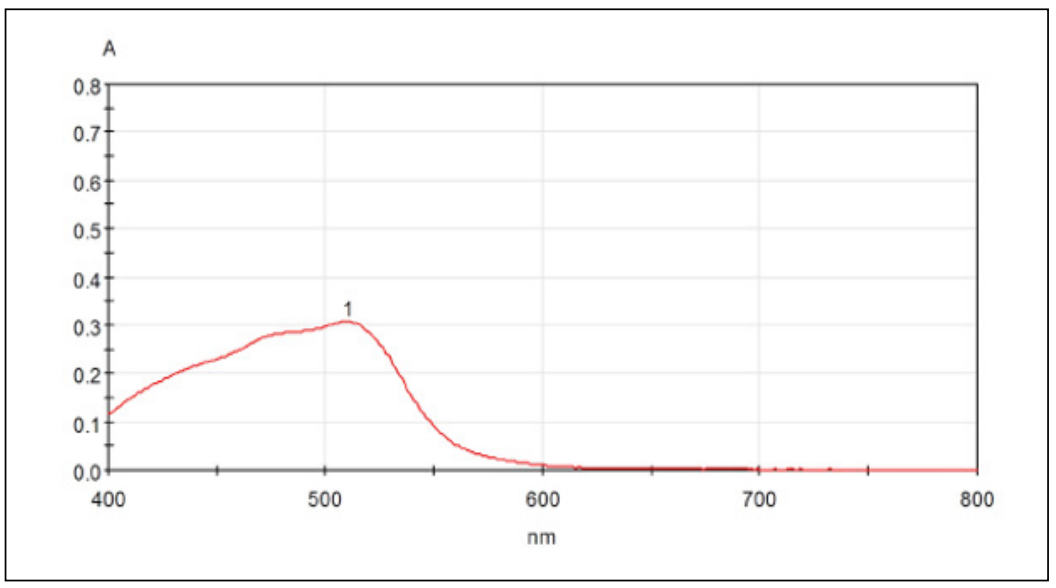

Gambar 3. Panjang gelombang serapan maksimum besi (II) sulfat heptahidrat dengan reagen ortho-fenantrolin, (1) $510 \mathrm{~nm}$ wavelength, 0,306 abs.

Tabe1 2. Hasil perhitungan aktivitas antioksidan ekstrak daun pacar kuku dengan spektrofotometer $\mathrm{UV}-\mathrm{V}$ is $\lambda$ maks $510 \mathrm{~nm}$.

\begin{tabular}{|ccccc|}
\hline Pengulangan & $\begin{array}{c}\text { Absorban } \\
(\mathbf{y})\end{array}$ & $\begin{array}{c}\text { Konsentrasi } \\
(\mathbf{x})\end{array}$ & $\begin{array}{c}\text { Konsentrasi rata-rata } \\
(\mathbf{x i})\end{array}$ & $\begin{array}{c}\text { Aktivitas Antioksidan } \\
\text { (mmol Fe (II)/100 g) }\end{array}$ \\
\hline \multirow{2}{*}{1} & 0,203 & 0,2845 & & \\
& 0,201 & 0,2829 & 0,2834 & 2,81 \\
& 0,201 & 0,2829 & & \\
2 & 0,204 & 0,2852 & & 2,83 \\
& 0,205 & 0,2860 & 0,2855 & \\
& 0,204 & 0,2852 & & 2,83 \\
3 & 0,207 & 0,2875 & & \\
& 0,204 & 0,2852 & 0,2860 & $\mathbf{2 , 8 2} \pm \mathbf{0 , 0 1}$ \\
& 0,204 & 0,2852 & & \\
& Rata-rata & & & \\
\end{tabular}


Ekstrak etanol sebanyak $100 \mathrm{mg} / 10 \mathrm{ml}$ diuji dengan metode FRAP dan diukur pada panjang gelombang $510 \mathrm{~nm}$ memiliki aktivitas antioksidan sebesar 2,82 mmol Fe(II)/100 g. Prinsip dari metode FRAP adalah berdasarkan kemampuan senyawa antioksidan berupa fenolat mereduksi ion Fe (III) menjadi Fe (II) membentuk kompleks dengan ortho-fenantrolin berwarna jinggamerah. Berdasarkan penelitian Susantika et. al. [20] diketahui aktivitas asam galat sebagai pembanding uji aktivitas antioksidan hasilnya yaitu 9,34 mmol Fe(II)/100 g. Dari hasil yang didapat, setelah dibandingkan dengan aktivitas antioksidan asam galat maka hasil aktivitas antioksidan ekstrak etanol daun pacar kuku lebih rendah dibandingkan aktivitas antioksidan asam galat.

\section{Kesimpulan}

Berdasarkan hasil penelitian ini dapat disimpulkan bahwa ekstraksi menggunakan pelarut etanol 70\% mempunyai rendemen ekstrak 36,05\% dari 500 gram simplisia. Karakterisasi simplisia dan ekstrak etanol daun pacar kuku telah sesuai dengan standar. Kadar fenolat total daun pacar kuku yaitu 16,02 g/100 g dan aktivitas antioksidan daun pacar kuku sebesar 2,82 mmol Fe(II)/100 g. Dibandingkan aktivitas antioksidan asam galat, aktivitas ekstrak daun pacar kuku lebih rendah.

\section{Referensi}

[1] Badan POM RI. Acuan Sediaan Herbal Vol. 7 Edisi I. Direktorat Obat Asli Indonesia; 2012.

[2] Hasiani VV, Ahmad I, Rijai L. Isolasi jamur endofit dan produksi metabolit sekunder antioksidan dari daun pacar (Lawsonia inermis L.). Jurnal Sains dan Kesehatan. 2015;1(4):146-153.
[3] Das PK, Mondal AK. Studies on traditional 'mehendi' used as herbal colour with special references to its antimicrobial activity and pigment profile by TLC. International Journal of Science and Nature. 2012;3(4):799-804.

[4] Marc EB, Nelly A, Annick DD, Frederic D. Plants used as remedies antirheumatic and antineuralgic in the traditional medicine of Lebanon. J Ethnopharmacol. 2008;120(3):315-334.

[5] Gbolade AA. Inventory of antidiabetic plants in selected districts of Lagos State, Nigeria. J Ethnopharmacol. 2009;121(1):135-139.

[6] Wiem A, Smail A, Wissem M, Faleiro M, Miguel M. Antioxidant, antiinflammatory and anti-acetylcholinesterase activities of leaf, flower and seed aqueous extracts of Lawsonia inermis from Tunisia. Int. J. Pharm. Pharm. Sci. 2014;6(5):445-452.

[7] Hosein HKM, Zinab D. Phenolic compound and antioxidant activity of henna leaves extracts (Lawsonia inermis). World Journal of Dairy \& Food Sciences. 2007;2(1):38-41.

[8] Departemen Kesehatan Republik Indonesia. Parameter Standar Umum Ekstrak Tumbuhan Obat. Jakarta: Departemen Kesehatan Republik Indonesia; 2000

[9] Prakash A, Rigelhof F, Miller E. Antioxidant activity. Medallion Laboratories: Analytical Progress. 2001;19(2):1-6.

[10] Mandal S, Yadav S, Nema RK. Antioxidant: a review. Journal of Chemical and Pharmaceutical Research. 2009;1(1):102-104.

[11] Gordon $\mathrm{MH}$. The mechanism of antioxidants actions in vitro. Di dalam: Hudson BJF, editor. Food Antioxidant. Elsevier Applied Science. 1990:1-18.

[12] Fluck H, Jaspersen SR. Medicinal Plants and Their Uses. London: W. Foulsham \& Co. Ltd; 1976.

[13] Raskin I, Ripoll C. Can an apple a day keep the doctor away?. Current Pharmaceutical Design. 2004;10(27):3419-3429.

[14] Departemen Kesehatan Republik Indonesia. Suplemen II Farmakope Herbal Indonesia. Jakarta: Depkes RI; 2010.

[15] Departemen Kesehatan RI. Farmakope Indonesia Edisi IV. Jakarta: Departemen Kesehatan RI; 1995.

[16] Kementerian Kesehatan RI. Farmakope Herbal Indonesia Suplemen 3 Edisi I. Jakarta: Dirjen Pelayanan Farmasi dan Alat Kesehatan, Kemenkes RI; 2013.

[17] Andayani R, Maimunah, Lisawati Y. Penentuan aktivitas antioksidan, kadar fenolat dan likopen pada buah tomat (Solanum lycopersicum L.). Jurnal Sains dan Teknologi Farmasi. 2008;13(1):31-37.

[18] Agoes, G. Teknologi Bahan Alam (edisi revisi). Bandung: Penerbit ITB; 2007.

[19] Waterhouse AL. Folin ciocalteau micro method for total phenol in wine. American Journal of Enology and Viticulture. 1999;28:1-3.

[20] Susantika M. Penentuan kadar fenolat total dan uji ativitas antioksidan dari ekstrak etanol kulit batang asam kandis. [Skripsi]. Padang: Fakultas Farmasi Universitas Andalas; 2016. 